\title{
Temporal and geographic evolution of longstanding Crohn's disease over more than 50 years
}

\author{
Hugh James Freeman MD
}

HJ Freeman. Temporal and geographic evolution of longstanding Crohn's disease over more than 50 years. Can J Gastroenterol 2003;17(12):696-700.

\begin{abstract}
Data on the natural history of longstanding Crohn's disease are very limited. After searching a clinical database of over 1000 patients with Crohn's disease, it was determined that eight patients (five women, three men) had disease documented for over 50 years. In spite of complex histories with either stricturing or penetrating complications, all currently have either no symptoms or minimal disease activity, often without the need for ongoing pharmacological treatment. Most significantly, their clinical courses were all characterized by prolonged asymptomatic periods, often for more than a decade, before the recurrence of symptomatic disease. Pathological findings in all patients revealed granulomatous inflammatory disease, often recurring intermittently over many decades. Moreover, the location of the findings implied that the disease has a tendency to evolve, not only in a temporal dimension, but also extending geographically within the gastrointestinal tract. These clinical and pathological features in longstanding Crohn's disease suggest that recurring or multiple discrete initiating events, rather than a single initiating event, could be involved in the etiology and pathogenesis of Crohn's disease.
\end{abstract}

Key Words: Crohn's disease; Natural history of Crohn's disease; Perforation; Stenosis

\author{
Évolution spatio-temporelle de la maladie de \\ Crohn de longue date, remontant à plus de \\ 50 ans
}

\begin{abstract}
Il existe très peu de données sur l'évolution naturelle de la maladie de Crohn de longue date. Après une recherche dans une base de données cliniques comptant plus de 1000 patients atteints de la maladie de Crohn, l'on n'a relevé que huit cas documentés ( 5 femmes, 3 hommes) remontant à plus de 50 ans. Malgré une évolution complexe, accompagnée de lésions sténosées ou pénétrantes, tous les patients présentaient au moment de la recherche peu ou pas de symptômes, et ce, bien souvent, sans traitement médicamenteux prolongé. Point encore plus important, l'évolution clinique se caractérisait dans tous les cas par des périodes prolongées de maladie asymptomatique, souvent de plus d'une dizaine d'années, avant l'arrivée d'un nouvel épisode symptomatique. L'examen pathologique a révélé chez tous les patients une maladie inflammatoire granulomateuse, évoluant souvent par poussée sur plusieurs décennies. De plus, l'emplacement des foyers d'inflammation tendait à montrer que la maladie évolue non seulement dans le temps mais aussi dans l'espace en s'attaquant à d'autres parties du tractus gastro-intestinal. Ces observations cliniques et pathologiques de la maladie de Crohn de longue date donnent à penser que la survenue d'événements récurrents ou de plusieurs événements déclencheurs, plutôt que d'un seul, pourrait être mise en cause dans l'étiologie et la pathogenèse de la maladie de Crohn.
\end{abstract}

$\mathrm{O}$ ne of the most quoted historical papers on Crohn's disease was based on a clinical experience accumulated in 14 patients with disease confined to the region of the distal ileum (1). Although published in 1932, similar changes had already been recorded more than a century earlier by Morgagni in 1769 (2), as well as in earlier publications by others (3). It was also suggested that this chronic nontuberculous granulomatous process could extend into or involve other parts of the alimentary tract. However, the true appreciation that Crohn's disease was a far more extensive disease process only followed later development and refinement of different imaging modalities, including radiographic, endoscopic and histopathological methods. Indeed, the data obtained using these modern clinical tools permitted the evolution of a simplified classification system for Crohn's disease and its application in clinical practice $(4,5)$. Recently, this schema has also been used to evaluate epidemiological and familial patterns of disease involvement (6), along with disease complications such as perforation and malignancies $(7-11)$.
Even now, there is only very limited information from welldefined populations on the natural history of Crohn's disease (12-14). During a recent evaluation of longstanding disease over at least two decades (15), a small group emerged with detailed documentation for more than 50 years. Although these patients provide an account of some of the inherent historical difficulties in confirming a diagnosis of Crohn's disease, the follow-up data, up to and including 2003 data, allowed exploration of this heterogeneous clinical process in continuous and longstanding Crohn's disease documented over many decades.

\section{METHODS}

A clinical database with over 1000 patients with Crohn's disease evaluated by the investigator and followed for over a decade was used (5-11). From this database, the natural history and clinical behaviour of 150 patients with longstanding Crohn's disease defined over 20 years was detailed (15). The present report describes findings in eight patients with disease documented for

Department of Medicine, Division of Gastroenterology, University of British Columbia, Vancouver, British Columbia

Correspondence: Dr Hugh Freeman, Gastroenterology, University of British Columbia Hospital, 2211 Wesbrook Mall, Vancouver,

British Columbia V6T 1W5. Telephone 604-822-7216, fax 604-822-7236, e-mail hugfree@shaw.ca

Received for publication June 25, 2003. Accepted September 30, 2003 
TABLE 1

\begin{tabular}{|c|c|c|c|c|}
\hline $\begin{array}{l}\text { Case } \\
\text { number }\end{array}$ & $\begin{array}{l}\text { Current } \\
\text { age/sex }\end{array}$ & $\begin{array}{l}\text { Disease } \\
\text { location }\end{array}$ & $\begin{array}{c}\text { Upper GI } \\
\text { disease }\end{array}$ & Behaviour \\
\hline 1 & $65 / M$ & Ileocolic & No & $S$ \\
\hline 2 & $76 / F$ & Ileocolic & No & NSNP \\
\hline 3 & $68 / F$ & Ileocolic & Yes & $S$ \\
\hline 4 & $86 / F$ & Ileocolic & No & $P$ \\
\hline 5 & $75 / \mathrm{F}$ & Ileocolic & No & $S$ \\
\hline 6 & $68 / M$ & Ileal & Yes & $S$ \\
\hline 7 & $70 / \mathrm{M}$ & Ileocolic & Yes & $P$ \\
\hline 8 & $72 / \mathrm{F}$ & Ileal & Yes & $S$ \\
\hline
\end{tabular}

All patients are currently alive and were last seen in 2003. Clinical classification was based on the Vienna System (4). F Female; Gl Gastrointestinal; M Male; NSNP Nonstricturing and nonpenetrating disease; $P$ Penetrating disease; S Stricturing disease

over 50 years. The findings in these cases are summarized in Tables 1 and 2 .

\section{CASE PRESENTATIONS}

Case 1

A 65-year-old male psychiatrist, born in the United Kingdom, developed abdominal pain in 1950 and barium studies in London showed an isolated distal ileal stricture. In 1953, this stricture was resected, revealing granulomas, and a diagnosis of possible ileal tuberculosis was considered but not established. In 1959, recurrent abdominal pain led to another ileal resection and a diagnosis of Crohn's disease. In 1960, his clinical course was complicated by anemia. This was treated with iron and vitamin $\mathrm{B}_{12}$. He emigrated to Toronto, Ontario, and in 1962, a further ileocolonic resection was done for recurrent disease. He moved to Vancouver, British Columbia, and in 1968, the abdominal pain recurred. Gallstones were detected and an open cholecystectomy with common bile duct exploration was done. Recurrent bouts of intestinal obstructive symptoms led to detection of recurrent 'neoterminal' ileal disease. Despite steroids, a further ileocolonic resection was required in 1972. Granulomatous inflammation was present. In 1975, abdominal pain recurred. Sulfasalazine was initiated at a dose of $4 \mathrm{~g}$ to $5 \mathrm{~g}$ daily, with symptom resolution. In 1982, recurrent abdominal pain led to the detection of another ileal stricture. In 1991, after courses of steroids, another ileocolic resection was done. Granulomatous inflammation was present with numerous multinucleated giant cells. In 1992, incision and drainage of a wound abscess was done. Diarrhea developed that responded to cholestyramine. In 1993, an incisional hernia was repaired. In 1995, diarrhea recurred but fecal cultures showed Yersinia enterocolitica. Treatment with ciprofloxacin led to resolution of the diarrhea. In 1995, he retired from clinical practice, and, in 1996, suffered a myocardial infarction complicated by a ventricular aneurysm and arrhthymia. In 2000, intermittent constipation developed. Colonoscopy and biopsies were normal and barium radiographs of his upper gastrointestinal tract, including small intestine, were normal (except for a shortened intestine). Follow-up in 2003 revealed that he was clinically well, using only periodic lansoprazole for heartburn.

\section{Case 2}

A 76-year-old woman was first labelled with a diagnosis of 'ulcerative colitis' in 1948. Because of repeated bouts of
TABLE 2

Ages of reported clinicopathological changes

\begin{tabular}{lccc}
\hline $\begin{array}{l}\text { Case } \\
\text { number }\end{array}$ & $\begin{array}{c}\text { Age at symptom } \\
\text { onset (years) }\end{array}$ & $\begin{array}{c}\text { Resection } \\
\text { number }\end{array}$ & $\begin{array}{c}\text { Age at discovery } \\
\text { of first/last } \\
\text { granuloma (years) }\end{array}$ \\
\hline 1 & 12 & 5 & $16 / 53$ \\
2 & 21 & 2 & $47 / 63$ \\
3 & 14 & 3 & $14 / 60$ \\
4 & 16 & 1 & $28 / 66$ \\
5 & 25 & 1 & $38 / 38$ \\
6 & 17 & 3 & $27 / 64$ \\
7 & 18 & 5 & $24 / 65$ \\
8 & 20 & 3 & $20 / 59$ \\
\hline
\end{tabular}

Granulomatous inflammation was detected in resected intestine or endoscopic biopsies. For case 5, granulomatous inflammation was reported on only one occasion

diarrhea and bleeding despite treatment with sulfasalazine and steroids, a subtotal colectomy was eventually done in 1971 . Original pathological materials were not available for review and the pathology report did not describe granulomatous inflammation. In 1974, the residual colon was resected and an ileostomy was created. Granulomatous colitis with discrete multifocal ulceration was noted. In 1990, metastatic colon cancer with lymph node involvement was diagnosed in the patient's brother. Because of concurrent development of intermittent mucopurulent and sanguinous ileostomy drainage, she was referred for testing to exclude intestinal cancer. Enteroscopy revealed friable ileal mucosa with focal serpinginous ulcerations $38 \mathrm{~cm}$ from the stoma. A biopsy showed granulomatous inflammation, and a diagnosis of Crohn's disease with ileal involvement was made. Small intestinal barium studies and computed tomography scans were normal. Administration of oral 5-aminosalicylate (5-ASA) was associated with resolution of symptoms. She ceased use of this medication after about one year. In 2003, she was clinically well without medications.

\section{Case 3}

A 68-year-old woman was admitted to a hospital in Iowa, USA in 1951 with an acute abdomen, thought to be possible appendicitis. Laparotomy revealed an ileitis. The distal $20 \mathrm{~cm}$ of ileum was resected and granulomatous inflammation was reported. Following surgery, she had occasional episodes of nonbloody diarrhea that responded to intermittent sulfasalazine. In 1988, she was hospitalized in Vancouver, British Columbia, for abdominal pain. Recurrent ileal Crohn's disease was defined and a further ileocolonic resection was done. Abdominal pain, bloody diarrhea and weight loss were partially responsive to oral 5-ASA and courses of steroids. By 1997, recurrent episodes of obstruction occurred. Endoscopic studies showed ileal ulceration along with histological evidence of granulomatous inflammation in the gastric antrum. After failed steroid treatment, another $32 \mathrm{~cm}$ of the distal ileum and proximal colon were resected. A cholecystectomy for gallstones was also done. Intestinal sections showed granuloma with multinucleated giant cells. Unfortunately, her diarrhea persisted. An oral 5-ASA preparation $800 \mathrm{mg}$ twice daily was administered along with a wheat-free diet with resultant improvement. Because of weight loss (over $15 \mathrm{~kg}$ ), however, she was referred for testing to exclude celiac disease. 
Endoscopic studies were normal except for focally active gastritis. No granulomas were detected. Her small intestinal biopsies were normal. The colon was normal but biopsies showed some nongranulomatous inflammation. Diarrhea resolved with cholestyramine and a low-fat diet. By 2002, she had regained her weight, and in 2003 she remained clinically well on no medications.

\section{Case 4}

An 84-year-old woman developed an acute abdomen in 1933 and an appendectomy was done for appendicitis. In 1945, an anal fistula was resected before a pregnancy. Granulomatous inflammation was reported in the resected tissue. Following her pregnancy, abdominal pain and diarrhea developed and 'colitis' was diagnosed. In 1971, barium studies revealed $50 \mathrm{~cm}$ of distal ileal disease, as well as involvement of the cecum and ascending colon. Sulfasalazine was prescribed and her symptoms resolved. In 1975, recurrent abdominal pain with fever and weight loss developed, thus, surgical treatment was recommended. However, the patient obtained an independent review at the Mayo Clinic in Rochester, Minnesota, USA, advising against intestinal resection. Recurrent episodes of intestinal obstruction followed over the next five years requiring repeated hospitalizations in Vancouver. In 1980, pyoderma gangrenosum developed and spontaneously resolved. In 1981, abdominal pain recurred but she remained resistant to surgical treatment and responded well, but only temporarily, to intravenous antibiotics. Repeated bouts of fever and abdominal pain were treated with intermittent courses of oral Septra (Glaxo Wellcome Inc, Canada). In 1984, an ileocolic resection and removal of an ileosigmoid fistula were required. The resected specimen showed changes of Crohn's disease with granulomatous inflammation, including multinucleated giant cells. No further gastrointestinal symptoms have occurred since that time. In 1985, a left ureteral calculus was endoscopically extracted. In 1999, she suffered repeated episodes of paroxysmal atrial fibrillation treated to the present time with antiarrhythmia medications and coumadin anticoagulation. In 2003, she was otherwise clinically well on no other medications.

\section{Case 5}

A 75-year-old woman was diagnosed with Crohn's disease of the ileum in 1952 in Boston, Massachussetts, USA, after presentating with fever and an abdominal mass. She was treated with sulfasalazine but developed a skin rash. Because abdominal pain and weight loss failed to respond to intravenous steroids, ileal resection and right hemicolectomy were done in 1965. Pathological studies showed granulomatous inflammation. In addition, a cholecystectomy for gallstones was done. Because of subsequent diarrhea, she had repeated endoscopic studies of her upper and lower gastrointestinal tracts in Boston. No mucosal disease was detected. She moved to Vancouver in 1982. Because of abdominal pain and diarrhea, barium and endoscopic studies with biopsies were repeated and were normal, except for shortened intestine. In 1988, pains in her extremities led to a diagnosis of mononeuritis multiplex involving the right ulnar and sural nerves. In 1989, a brainstem arteriovenous malformation was diagnosed and later surgically treated in San Francisco, California, USA. This resulted in some residual right hemiparesis. In 1992, recurrent abdominal pain led to endoscopic studies of her upper gastrointestinal tract and residual colon. Only nonspecific anastomotic inflammatory changes were detected. During a vacation in Honolulu, Hawaii, USA, in 1993, she redeveloped abdominal pain along with a skin rash. A 5-ASA hypersensitivity reaction was diagnosed and intravenous steroids were administered, leading to resolution. Further endoscopic studies in Vancouver were normal with no Crohn's disease detected. In 1994, abdominal pain and diarrhea recurred. Fecal cultures grew Aeromonas hydrophila and her symptoms resolved without treatment. In 1995, hematuria developed and a right kidney stone was treated with lithotripsy in Boston. In 1997, abdominal pain recurred and endoscopic study results were normal. In 2001, dysphagia and odynophagia developed after treatment of 'bronchitis' with clarithromycin. Endoscopy revealed candida esophagitis that was treated with mycostatin suspension. Except for occasional episodes of diarrhea, she has remained clinically well to 2003 on no medications.

\section{Case 6}

A 68-year-old man was diagnosed with Crohn's disease in 1951 in Vancouver. In 1961, a distal ileal resection was done and granulomas were present. In 1963, recurrent ileal disease was detected along with extensive cicatrizing involvement of the stomach and duodenum. A further ileocolic resection and gastroenterostomy were done. In 1975, he was hospitalized with a gastric ulcer, and treated with diet and oral antacids. In 1991, a spontaneous splenic rupture led to splenectomy. Later in 1991, recurrent abdominal pain led to a cholecystectomy for gallstones. In 1996, abdominal pain recurred and another ileocolic resection was done. In 1998, he was re-evaluated for diarrhea. Endoscopic studies showed duodenal stenosis, and duodenal bulb biopsies showed granulomatous inflammation. The stoma, however, was widely patent with histologically normal mucosa in the afferent and efferent limbs. Gastric mucosa showed reactive inflammatory changes presumed to be due to alkaline reflux. Inflammatory changes with narrowing and ulceration were present in the distal $10 \mathrm{~cm}$ of 'neoterminal' ileum, as well as in the colon. An 'antidumping' diet with cholestyramine led to resolution of his diarrhea. Oral budesonide, prescribed in 1999, was discontinued in 2001 because of limited clinical benefit. In 2003, he was asymptomatic on cholestyramine alone.

\section{Case 7}

A 70-year-old man first developed abdominal pain in 1951 while residing in Montreal, Quebec. Because of recurrent symptoms, barium studies done in Boston in 1956 led to a diagnosis of 'regional ileitis'. Treatment, initially with antibiotics and sulfa-containing medications and later steroids, only partially controlled symptoms. In 1958, bloody diarrhea developed and 'right-sided ulcerative colitis' was diagnosed in Montreal. Because of recurrent abdominal pain and diarrhea, an ileocolic resection was done with removal of $30 \mathrm{~cm}$ of the distal small bowel. Although deep linear ulcers in the distal small bowel and proximal colon were reported with granulomatous inflammation, including multinucleated giant cells, changes were interpreted to show 'ulcerative ileitis' and 'ulcerative colitis'. A month later, a fistulectomy was done for an anal fistula. In 1965, a psoas abscess developed with an ileal fistula, resulting in resection of $50 \mathrm{~cm}$ of the distal ileum. Granulomatous inflammation with clusters of epithelioid cells was detected. Postoperatively, hematemesis developed, and 
treatment included blood transfusion with 28 units and gastric cooling. Jaundice developed three months later, leading to admission for a diagnosis of 'serum hepatitis'. During hospitalization, radiographic studies of the small intestine showed extensive and recurrent regional ileitis despite 'maintenance' low-dose corticosteroids. In 1967, an abdominal wall abscess was drained and a further $25 \mathrm{~cm}$ of ileum with an enterocutaneous fistulous tract was resected. In 1969, a further $90 \mathrm{~cm}$ jejunoileal resection was done that included a complex enterocutaneous fistulous tract. In both resected specimens, granulomas with multinucleated giant cells were reported. In 1970, anemia (hemoglobin $85 \mathrm{~g} / \mathrm{L}$ with iron deficiency) was detected in spite of monthly vitamin B12 injections and prednisone. Iron supplements were provided. Radiographic studies showed recurrent small bowel stenosis with ulceration. Steroids were stopped. In 1972, he moved to Vancouver and no medications or further hospitalizations were required for a decade. In 1982, abdominal pain developed, leading to the detection of renal stones. In 1984, radiographic studies showed extensive small bowel involvement with Crohn's disease, including multiple strictures. Abdominal cramping pain resolved with administration of a lactose-free diet and reinstitution of sulfasalazine. Vitamin $B_{12}$ was also periodically administered. From 1985 to 1988 , he suffered from reflux symptoms that responded to antacids and, later, to ranitidine and domperidone. In 1992, abdominal pain recurred along with fever. Radiographs showed a strictured small intestine with a dilated loop containing mobile filling defects.

Endoscopic evaluation of the colon and upper gastrointestinal tract and biopsies were normal. Symptoms appeared to resolve with metronidazole but then recurred. An abdominal wall abscess developed with an enterocutaneous fistula. A $25 \mathrm{~cm}$ small bowel resection was done to include a strictured segment of small bowel with an enterocutaneous and enteroenteric fistula. Two enteroliths were also present in the resected segment. In 1993, swelling of his lip and oral ulceration developed. Resection of tissue from an edentulous ridge revealed noncaseating granulomas. The changes resolved without treatment except for sulfasalazine. In 1996, his abdominal pain recurred. Endoscopic and radiographic studies showed no significant changes except for a markedly shortened small intestine.

Abdominal ultrasound showed multiple stones. Reflux symptoms recurred and were controlled with oral pantoprazole. In 1998, recurrent pain led to endoscopic evaluations. Gastric and duodenal erosions were seen and biopsies showed granulomatous inflammation with multinucleated giant cells. A course of budesonide along with herbal teas improved symptoms. In 2000, increased anorectal drainage with localized perineal induration was noted, and treatment with oral metronidazole and ciprofloxacin led to temporary resolution. In 2002, recurrent abdominal pain developed. Repeat endoscopic studies showed esophageal, gastric and duodenal erosions in spite of daily pantoprazole; esomeprazole provided relief of abdominal pain and symptomatic reflux. In 2003, he was on daily esomeprazole and periodic parenteral vitamin $B_{12}$. Occasionally, he was treated with intermittent metronidazole for recurrent perianal sepsis.

\section{Case 8}

A 72-year-old woman had two laparotomies in 1949 after presenting with abdominal pain thought to be due to appendicitis.
The first operation led to resection of about $100 \mathrm{~cm}$ of distal ileum; 'regional enteritis' was diagnosed. Review of file photographs of the resected specimen and pathology reports with granulomatous inflammatory change were consistent with ileal involvement from Crohn's disease. Later in the same year, after development of a bowel obstruction, a second laparotomy was done for lysis of adhesions. Additional intestine was resected but the length was not defined. In 1984, intermittent diarrhea, bulky stools and weight loss were reported. A fecal fat determination revealed $28 \mathrm{~g}$ per day. Small bowel biopsies showed moderately severe but patchy inflammatory changes initially interpreted to be consistent with celiac disease. However, a gluten-free diet had no effect on her symptoms, weight or fecal fat excretion. She was treated with prednisone, but in 1985, a bowel obstruction from an anastomotic stricture led to resection of another $10 \mathrm{~cm}$. Subsequent treatment included oral supplements of calcium, zinc and multivitamins. In 1988, duodenal biopsies showed a patchy, moderately severe inflammatory process with mucosal granulomas consistent with Crohn's disease. In 1989, weakness and difficulties with her balance developed. Neurological evaluation including electrophysiological studies showed both neuropathic and myopathic changes. Muscle biopsy studies, including electron microscopy and histochemical studies, were reported to show an inclusion body myositis. Despite this neuromuscular disorder, she remains well in 2003 on the same oral supplements.

\section{DISCUSSION}

Crohn's disease is a chronic inflammatory granulomatous disease that involves different sites along the length of the gastrointestinal tract. Genetic and environmental factors play a role in its etiology and pathogenesis and recent studies have described its female predominance, often familial nature, and its clinical characterization with a high rate of stricturing and penetrating complications $(5,6)$. In an investigation of the natural history and clinical behaviour of Crohn's disease in patients seen over at least two decades, clinical features were observed to change and evolve with time, indicating that it is a phenotypically dynamic, rather than static disorder (15). The present report further explored these features of Crohn's disease present in patients with disease documented for more than 50 years. The longitudinal data here confirm that Crohn's disease is an intermittently progressive inflammatory process, punctuated by periods necessitating repeated hospitalizations and eventual surgical resections, but often having extended, even decade-long periods or longer without symptoms or with minimal or very limited disease activity.

Precise clinical and pathological correlation in Crohn's disease during the prolonged course of this clinical disorder has been difficult. Some of the major, albeit historical, pathological descriptions of Crohn's disease avoided reporting the specific temporal sequence of progression of anatomical lesions (16). However, in a previous, carefully done study by Kelly and Sutherland (17), the ongoing chronological sequence of pathological changes with recurrent Crohn's was explored. Their results suggested a progression from early findings of small ulcers or granulomas to later definition of sinuses and strictures complicating large ulcers (17). This suggests that there may be a single or relatively localized period of time for this granulomatous inflammatory process to be initiated followed by progression to its complications, including strictures or fistulous changes. In the cases described in the present 
paper, however, almost all had granulomatous inflammatory changes detected in specimens resected during at least one, and usually multiple, surgical or endoscopic procedures, but these events were sometimes separated by many decades. Assuming that this earlier hypothesis of a chronological sequence of pathological changes is correct, detection of granulomatous changes in both surgically-resected and endoscopic materials over many decades suggests that there may be multiple or recurring initiating events with different rates of progression in individual patients with Crohn's disease. Alternatively, but less consistent with the earlier hypothesis (17), granulomas could reflect ongoing active inflammation, present even with subclinical or asymptomatic disease, but having no apparent temporal or chronological sequence to the pathological changes in Crohn's disease.

In addition to this temporal dimension, clinical features in Crohn's disease may also vary depending on the geographic localization of the inflammatory process along the length of the gastrointestinal tract. Interestingly, in patients described here, many had granulomas detected over time in different sites, including gastric and duodenal mucosa, but later in their clinical course. In addition, a single patient also had oral granulomas documented in an oral biopsy and another had granulomas in ileal biopsies decades after a proctocolectomy for colonic disease. Although these findings are not unusual and may only reflect evolving technology and a local enthusiasm over many years for granuloma detection, pathological events leading to granulomatous involvement in Crohn's disease may also require consideration of another, albeit 'geographic' dimension, the site of involvement along the length of the gastrointestinal tract. Definition of granulomatous inflammatory

\section{REFERENCES}

1. Crohn BB, Ginzburg L, Oppenheimer GD. Regional ileitis: A pathologic and clinical entity. J Am Med Assoc 1932;99:1323-9.

2. Morgagni GB. De Sedibus et Causis Morborum (The Seats and Causes of Disease). London: Millar and Cadwell, 1769. Facsimile of the 1769 edition. New York, Hafner, 1960.

3. Dalzeil TK. Chronic interstitial enteritis. Br Med J 1913;2:1068-70.

4. Gasche C, Scholmerich J, Brynskov J, et al. A simple classification of Crohn's disease: Report of a working party for the World Congress of Gastroenterology, Vienna 1998. Inflamm Bowel Dis 2000;6:8-15.

5. Freeman HJ. Application of the Vienna Classification for Crohn's disease to a single clinician database of 877 patients. Can J Gastroenterol 2001;15:89-93.

6. Freeman HJ. Familial Crohn's disease in single or multiple firstdegree relatives. J Clin Gastroenterol 2002;35:9-13.

7. Freeman HJ. Spontaneous free perforation of the small intestine in Crohn's disease. Can J Gastroenterol 2002;16:23-7.

8. Freeman HJ. Meckel's diverticulum in Crohn's disease. Can J Gastroenterol 2001;15:308-11.

9. Freeman HJ. Colorectal cancer complicating Crohn's disease. Can J Gastroenterol 2001;15:231-6.

10. Freeman HJ. Tabulation of myeloid, lymphoid and intestinal malignancies in Crohn's disease. Can J Gastroenterol 2002;16:779-84.

11. Freeman HJ. Appendiceal carcinoids in Crohn's disease. Can J Gastroenterol 2003;17:43-6. disease in the ileum many years after its colonic involvement, or gastroduodenal disease detected years after an ileocolic resection, suggests that if a single initiating event occurred, different tissues along the gastrointestinal tract may develop a granulomatous response at different rates, or alternatively, there are recurring initiating events. Alternatively, the 'sensitivity' of various gastrointestinal sites to a possible agent involved in the etiopathogenesis of Crohn's disease may differ, possibly related to a site-specific differential in intestinal permeability $(18,19)$ or a differing immunological response $(20)$ along the length of the gastrointestinal tract.

Taken together, clinical and pathological data accumulated over an extended time frame imply that Crohn's disease is a very heterogeneous disease with highly variable clinical courses. Time of initial diagnosis relative to disease onset and resultant evaluation during the disease course may differ substantially in individual patients. Crohn's disease is a dynamic, rather than static, process with the clinical and granulomatous pathological changes developing in both a temporal and geographical dimension. This has particularly important implications for clinical trials of therapeutic agents that focus on a relatively restricted time period during the course of Crohn's disease. Indeed, the apparent heterogeneity of symptomatic responses in clinical trials to a specific treatment, or even comparisons of placebos in different studies, may only reflect different stages of disease evolution in a variably progressive clinical disorder. Classification of disease that includes genetic or molecular markers that remain reproducible and 'reagentgrade' during the entire course of disease may be our best hope for future clinical studies and therapeutic trials of pharmacological and biological agents.

12. Schwartz DA, Loftus EV Jr, Tremaine WJ, et al. The natural history of fistulizing Crohn's disease in Olmstead County, Minnesota. Gastroenterology 2002;122:875-80.

13. Loftus EV Jr, Schoenfeld P, Sandbord WJ. The epidemiology and natural history of Crohn's disease in population-based patient cohorts from North America: A systematic review. Aliment Pharmacol Ther 2002;16:51-60.

14. Jess T, Winther KV, Munkeholm P, Langholz E, Binder V. Mortality and causes of death in Crohn's disease: Follow-up of a populationbased cohort in Copenhagen County, Denmark. Gastroenterology 2002;122:1808-14.

15. Freeman HJ. Natural history and clinical behavior of Crohn's disease extending beyond two decades. J Clin Gastroenterol 2003;37:216-9.

16. Morson BC, Dawson IMP. Gastrointestinal Pathology, 2nd edition. Oxford: Blackwell Scientific Publications, 1979:293-312.

17. Kelly JK, Sutherland LR. The chronological sequence in the pathology of Crohn's disease. J Clin Gastroenterol 1988;10:28-33.

18. Meddings JB, Gibbons I. Discrimination of site-specific alterations in gastrointestinal permeability in the rat. Gastroenterology 1998;114:83-92.

19. Meddings J. Barrier dysfunction in Crohn's disease. Ann NY Acad Sci 2000;915:333-8.

20. Camerini V, Panwala C, Kronenberg M. Regional specialization of the mucosal immune system. Intraepithelial lymphocytes of the large intestine have a different phenotype and function than those of the small intestine. J Immunol 1993;151:1765-76. 


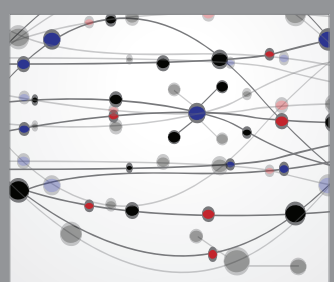

The Scientific World Journal
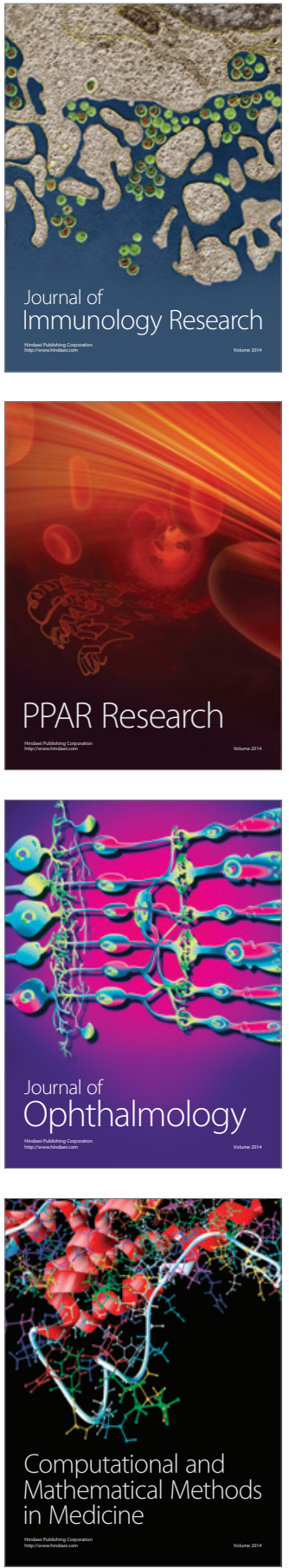

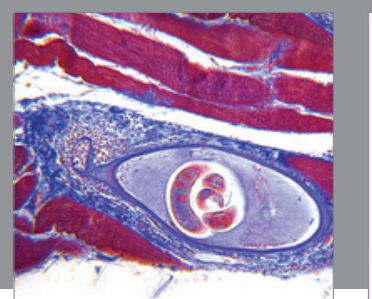

Gastroenterology Research and Practice

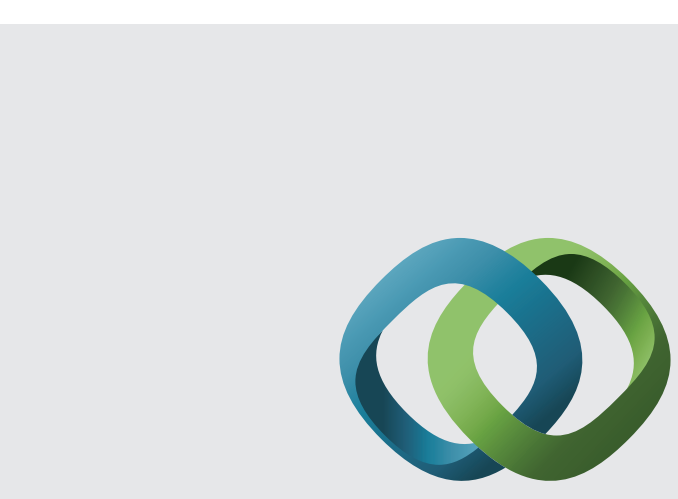

\section{Hindawi}

Submit your manuscripts at

http://www.hindawi.com
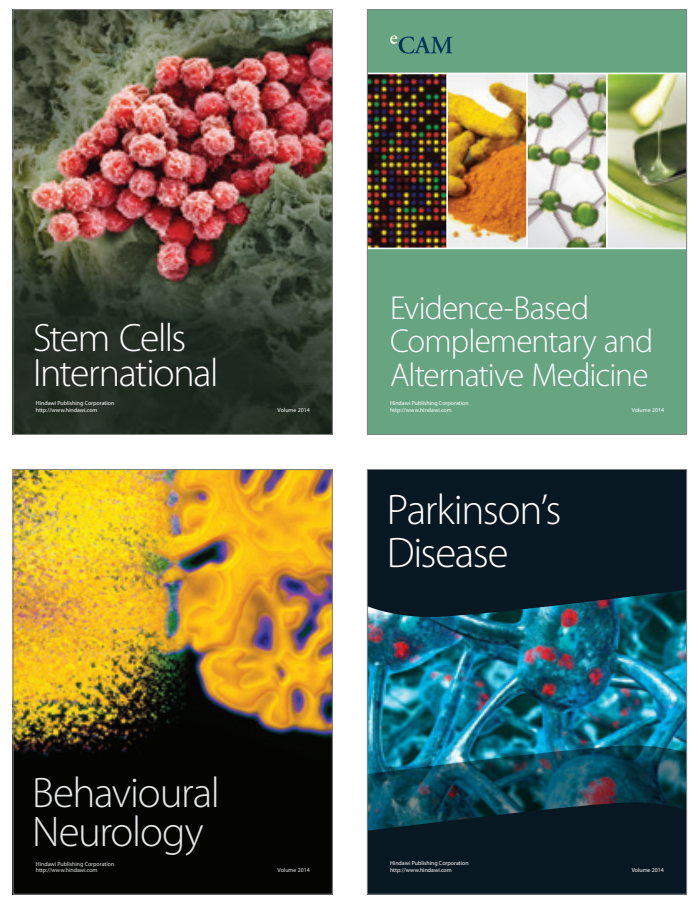
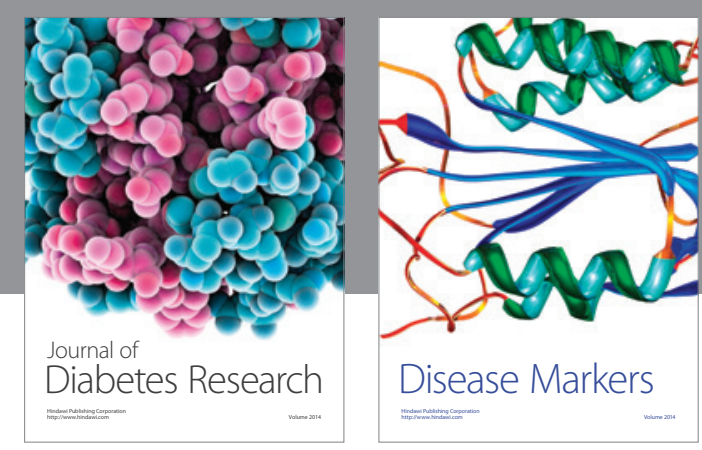

Disease Markers
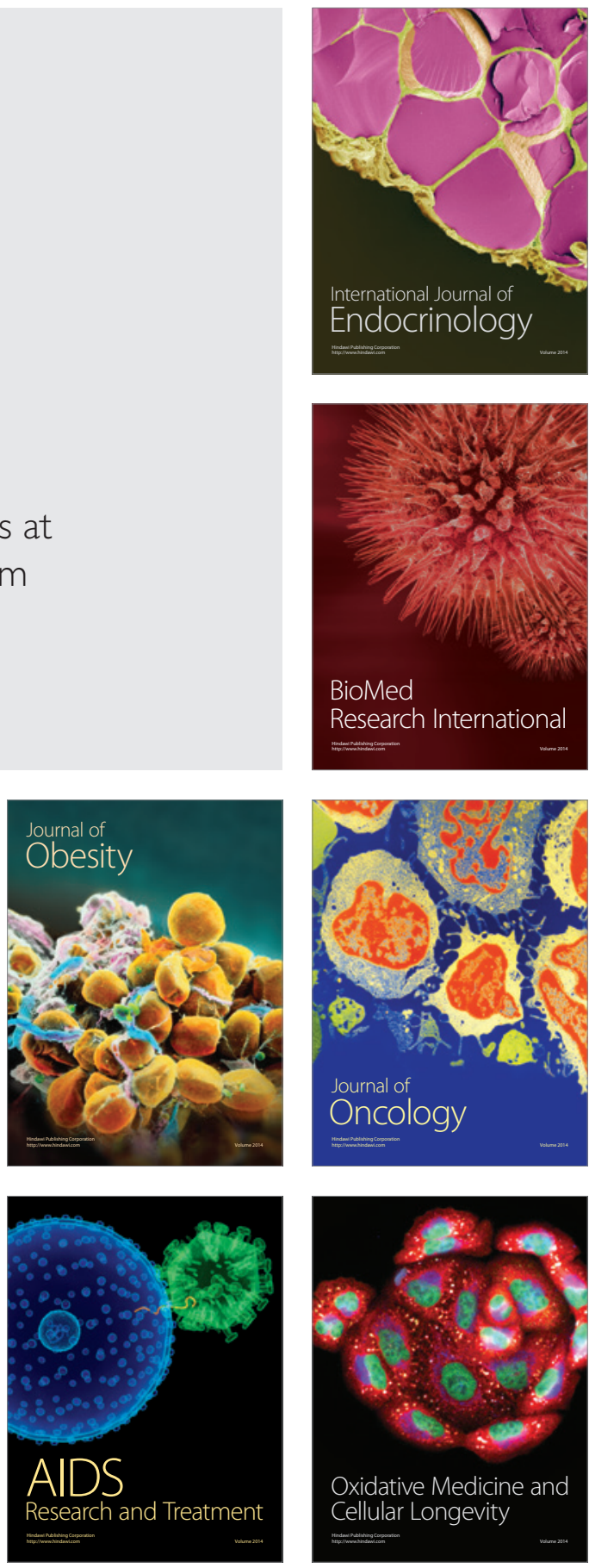